\title{
O Respeito pela Autonomia da Criança na Regulação das Responsabilidades Parentais
}

\author{
Respecting Minor's Autonomy in Child Custody Cases
}

\author{
Bárbara SANTA ROSA ${ }^{1,2}$, Francisco CORTE-REAL ${ }^{1,2,3}$, Duarte Nuno VIEIRA ${ }^{1,2,3}$ \\ Acta Med Port 2013 Nov-Dec;26(6):637-643
}

\section{RESUMO}

As decisões de custódia parental estão entre as mais difíceis de ser tomadas pelos tribunais. A possível coexistência de alegações de abuso da criança ou comportamentos desviantes/psicopatológicos dos progenitores aumenta a complexidade da tomada de decisão. Decorre da jurisprudência que a audição da criança se consagra como a forma mais lídima de auscultar o seu superior interesse. De facto, o menor tem direito a ser ouvido em todas as decisões que lhe digam respeito, devendo a sua vontade ser considerada de acordo com a sua idade, discernimento e maturidade. No entanto, as disputas de custódia configuram uma importante fonte de angústia para a criança, pelo que pedir-lhe que expresse a sua preferência em audiência pública, porventura na presença de ambos os progenitores, não é aconselhável, por razões que se prendem com a necessidade de a proteger de uma experiência potencialmente stressante. Há que privilegiar entrevistas em ambiente adequado, acessíveis e ajustadas à idade do menor. À Medicina e à Psicologia cabe o importante papel de avaliar as capacidades cognitivas, volitivas e emocionais do menor, facto essencial à adequada consideração da sua opinião de acordo com o seu grau de autonomia. Este ensaio analisa o contributo da perícia médico-legal e/ou psicológica para que o respeito pela autonomia do menor seja verdadeiramente considerado, nos casos de regulação das responsabilidades parentais. Conclui-se a necessidade de estabelecer uma relação de simbiose entre as perspetivas médica e judicial do conceito (aberto) do superior interesse da criança.

Palavras-chave: Autonomia Pessoal; Bem-Estar da Criança; Criança; Custódia da Criança/ legislação e jurisprudência; Dissidências e Disputas; Divórcio; Portugal.

\section{ABSTRACT}

Child custody decisions are among the most difficult for judges to make. The possibility of child abuse allegations or parents' deviant/ psychopathologic behaviours within this context, make the decision further complicated. Based on jurisprudence the listening of children opinion is a way to protect their best interest. In fact children have the right to express an opinion in all matters affecting their life. It should be given proper consideration to children opinion according with his/her age and maturity. Nonetheless custody disputes are emotionally draining issues. Asking the child to express an opinion during a public hearing, most likely in the presence of both parents, its not recommended because this is a potential stressful experience. Child interviews should take place in a proper environment and be set to their age. Medicine and Psychology have an important role in assessing children cognitive, emotional and volitional abilities, which is essential to properly account their opinions according to autonomy degree. This essay analyses the contribution of medico-legal and/or psychological exams to respect the autonomy of the child in cases of regulation of parental responsibilities. The conclusion is the need to establish a symbiotic relationship between the medical and legal perspectives of the (open) concept of child's best interests. Keywords: Child; Child Custody/ legislation and jurisprudence; Child Welfare; Dissent and Disputes; Divorce; Personal Autonomy; Portugal.

\section{INTRODUÇÃO}

As decisões de custódia estão entre as mais difíceis de ser tomadas pelos tribunais. O principal objetivo, nesta matéria, é o de atuar de acordo com o melhor interesse da criança, mas este conceito depende das noções, em constante mudança, de lei e equidade e dos princípios/ paradigmas científicos vigentes. Fazer justiça pode ser um trabalho complexo. Reconhecemos que se impõe o desafio de pensar uma ética que englobe a obrigação (moral) de promover, neste contexto, condições que potenciem a tomada de decisão autónoma pelo menor. Dedicamos assim este estudo à análise do atual/potencial contributo da medicina forense no que concerne ao respeito pela autonomia do menor, em sede de regulação das responsabilidades parentais.
Entende-se por autonomia a propriedade que a vontade possui de ser lei para si mesma, independentemente da natureza dos objetos do querer. O conceito de liberdade está inseparavelmente unido ao princípio da autonomia, ${ }^{1}$ que afirma a capacidade de autodeterminação do indivíduo. A Convenção sobre os Direitos da Criança, prevê o direito do menor ser ouvido em todas as decisões que the digam respeito, devendo a vontade deste ser considerada de acordo com a sua idade, discernimento e grau de maturidade. Permitir ao menor (de 18 anos) expressar a sua opinião respeita os seus direitos fundamentais e potencia decisões concordantes com o seu melhor interesse. As políticas públicas do início do século XXI assumem os direitos das crianças como uma preocupação prioritária, nas rela-

1. Instituto Nacional de Medicina Legal e Ciências Forenses. Delegação do Centro. Coimbra. Portugal.

2. Centro de Ciências Forenses (CENCIFOR). Coimbra. Portugal.

3. Faculdade de Medicina. Universidade de Coimbra. Coimbra. Portugal.

Recebido: 23 de Julho de 2013 - Aceite: 24 de Agosto de 2013 | Copyright @ Ordem dos Médicos 2013 
ções sociofamiliares, ${ }^{2}$ estabelecendo limites ao exercício da autoridade parental e impondo um dever positivo de respeito pela personalidade dos filhos. ${ }^{3} \mathrm{O}$ conteúdo da relação pais/filhos encontra-se assim subordinado ao princípio da negociação, considerando-se a dimensão afetiva o núcleo central desta relação. ${ }^{2}$ Decorre do exposto que, apesar de historicamente se ter desconsiderado a opinião do menor nas decisões de custódia parental, ${ }^{4}$ a tendência atual é atender à sua preferência, no veredito judicial, sempre que adequado.

A Medicina (designadamente as especialidades de Pediatria ou Psiquiatria da Infância e da Adolescência), complementando-se, se necessário, com exames de outras áreas do saber (nomeadamente Psicologia), pode, de acordo com as suas competências, desempenhar um importante papel, não só na distinção entre decisões ditadas por receio, capricho ou interpretação egocêntrica, características de determinadas idades, e decisões resultantes de uma reflexão mais amadurecida, mas também na avaliação da ampla gama de estádios de desenvolvimento (e portanto de autonomia), observados entre estes extremos.

\section{O RESPEITO PELA AUTONOMIA DO MENOR}

A autonomia da vontade corresponde ao progressivo desenvolvimento de uma consciência crítica dialógica, sendo um dos pressupostos básicos da convivência de sujeitos autónomos tomar o outro não como um objeto, mas como um sujeito que tem algo a dizer. Existem dois importantes conceitos subjacentes ao exercício da autonomia, são eles a competência do indivíduo e a voluntariedade da conduta. A competência é definida como a capacidade para entender a informação, emitir juízos e expor os desejos perante os outros. Este conceito está associado ao da autonomia não só pelo seu significado, mas também pelo seu fundamento, visto que uma pessoa autónoma é necessariamente competente para tomar decisões. ${ }^{5,6}$ No que respeita ao conceito da voluntariedade, este associa à autonomia o agir de acordo com a própria vontade, o que não exclui a existência de inevitáveis influências externas resultantes da relação dinâmica entre o sujeito e o ambiente. Neste ponto importa observar que a criança está mergulhada, desde os primeiros meses, numa atmosfera de regras, tornando-se extremamente difícil discernir o que vem dela própria, dos rituais que respeita, e o que resulta das circunstâncias/ círculo social.

Em Direito, a autonomia da vontade, intimamente relacionada com a capacidade de decidir, ultrapassa o campo meramente ético. Assim o princípio do respeito pela autonomia encontrará diferentes restrições de acordo com o momento de desenvolvimento cognitivo do menor. A construção da autonomia da vontade tal como o desenvolvimento da capacidade de decidir são processos cognitivos dinâmicos e contínuos, podendo subsistir ao longo de toda a vida. Tal facto dificulta a conciliação entre estes conceitos e as exigências jurídicas.

As teorias desenvolvimentistas contribuíram notavelmente para distinguir as capacidades cognitivas do adulto das da criança. Murray Thomas, ${ }^{9}$ inspirando-se nestas teorias, sintetizou o pensamento moderno do desenvolvimento da criança, considerando que cada indivíduo possui um legado genético único, conferindo-lhe um espetro distinto de capacidades intelectuais potenciais, que se desenvolvem, principalmente nas primeiras duas décadas de vida, atingindo diferentes graus de maturidade de acordo com as influências ambientais.

De acordo com Piaget, ${ }^{7}$ as crianças com idades compreendidas entre os dois e os sete anos não têm consciência dos seus direitos, obedecendo aos pais e demais adultos, que são um controle extrínseco à sua volição (vontade). Destes fatos, resulta a sugestionabilidade da criança, que possui ainda limitadas capacidades de memória e de raciocínio lógico. Estas características influenciam o alcance das suas perceções e considerações acerca de acontecimentos significativos. ${ }^{10}$ A capacidade de operar o pensamento concreto, e consequente compreensão das possíveis consequências dos seus atos em contexto social, aperfeiçoa-se na idade escolar (6-11 anos). A tomada de decisões passa a considerar valores, baseando-se em padrões e convicções de moralidade (ainda que em permanente mutação). Este amadurecimento completa-se na adolescência, com o desenvolvimento crescente da capacidade de abstração. Como consequência, é possível admitir que a partir dos 15 anos o indivíduo atinge as competências necessárias ao exercício da sua autonomia, que serão lapidadas pela "experiência de vida".

No entanto há que considerar cuidadosamente tais indicações etárias. Duas crianças da mesma idade podem encontrar-se em fases diferentes de desenvolvimento cognitivo, ou encontrando-se na mesma fase, não possuir a mesma capacidade de tomar decisões. Efectivamente a Teoria Ecológica de Bronfenbrenner explica estes desvios da norma Piagetiana como sendo, em parte, influenciados pelo contexto sociocultural. Importa ainda salientar que as crianças a partir dos sete anos, apesar de não terem consciência de que sabem decidir, estão na sua grande maioria aptas a fazê-lo. Não é, no entanto, de negligenciar que mantêm, até idades mais tardias, uma inconstância de valores, nomeadamente no que diz respeito à conceção do bem e do mal, facto que se repercute na sua capacidade de prever ou avaliar as consequências futuras de decisões atuais. ${ }^{11}$ Neste sentido, afirma Elizabeth Scott, ${ }^{12}$ que a ideia de que os adolescentes têm uma capacidade de tomar decisões semelhante à dos adultos é sustentada em dados de cariz acentuadamente empírico, colocando em causa a generalização destas conclusões a diferentes indivíduos, contextos e épocas. De facto, a opinião da criança deve ser avaliada de acordo com o caso em concreto e não aceite ou excluída apenas por questões etárias, uma vez que existem inúmeras variáveis a considerar na ponderação da opinião do menor.

Por outro lado, o juiz não tem (nem tem de ter) o adequado conhecimento do desenvolvimento cognitivo do menor nem tão pouco da dinâmica das relações familiares, o que lhe limita a capacidade de avaliar e atuar de acordo 
com a sua maturidade e interpretar adequadamente as suas manifestações de vontade. Acresce que, dadas as características da audição do menor pelo juiz, dificilmente poderá ser disponibilizado o período de tempo necessário para averiguar se este possui um conhecimento adequado sobre as alternativas de que dispõe, bem como dos riscos e benefícios das mesmas, premissas essenciais para que a decisão não se limite a espelhar a opinião da figura parental de referência. É ainda de atentar que as disputas de custódia parental configuram uma importante fonte de angústia para a criança pelo que pedir-lhe que expresse a sua preferência em audiência pública, porventura na presença de ambos os progenitores, não é aconselhável, por razões que se prendem com a necessidade de a proteger de uma experiência potencialmente stressante.

A complexidade e controvérsia do tema é merecedora de numerosas publicações, mas, até à data pouco foi escrito acerca da repercussão da interferência judicial nas escolhas do menor em assuntos como a custódia e o local de residência. É ainda assim inegável, no sentido de respeitar a sua autonomia, a necessidade de privilegiar entrevistas em ambiente adequado, acessíveis e ajustadas à idade do menor. A audição do menor não tem obrigatoriamente que ser efectuada pelo tribunal, podendo ser suficientes elementos que venham ao conhecimento do juiz por via de relatório/informações prestadas por aqueles que com ele contactaram. Idealmente a entrevista deve ser conduzida por um profissional especializado numa área do saber adequada, nomeadamente Psicologia Infantil ou Psiquiatria da Infância e da Adolescência, assegurando-se assim que os procedimentos aplicados são acessíveis e ajustados à sua idade. Avaliar, caso a caso, as capacidades cognitivas, volitivas e emocionais do menor é essencial para a equidade da decisão judicial. O perito não deve ser nomeado pelas partes, promovendo-se a neutralidade e objectividade da avaliação. Sempre que o relatório/testemunho pericial seja insuficiente para satisfazer as necessidades do juiz a audição do menor em sede de tribunal deverá ser voluntária, respeitosa, inclusiva, permitindo que a criança, na posse das informações relevantes, expresse a sua opinião. Não devem ser negligenciadas as limitações deste tipo de entrevista nem o seu potencial impacto emocional negativo.

Exceto na presença de provas de que a opinião expressada pelo menor é desadequada, podendo colocá-lo numa situação de risco, o tribunal deverá considerá-la em prol do seu melhor interesse. Afigura-se-nos que muitos dos pais envolvidos em processos de custódia desempenharam a sua função de educadores irrepreensivelmente, sem qualquer necessidade de intervenção da justiça. Nestes casos poderá não ser possível prever qualquer desvantagem em atender ao desejo do menor. Acresce que uma ordem judicial no sentido de obrigar o menor a viver com um progenitor pode redundar em desobediência, prolongando o processo e a litigância.

\section{PRESSUPOSTOS JURÍDICOS}

Assistimos a uma desjuridificação e desjudicialização da resolução dos conflitos da família, considerando-se as normas sociais e jurídicas uma intrusão na vida privada e na esfera da autonomia individual. ${ }^{13}$ Neste contexto surgiram parcerias do Estado com as autarquias locais e com as entidades associativas da comunidade, nomeadamente as Comissões de Protecção de Crianças e Jovens, enquanto instituições oficiais não judiciárias, que têm as suas competências estabelecidas na Lei de Protecção de Crianças e Jovens em Perigo (LPCJ) e que intervêm não no sentido de orientar o comportamento privado das pessoas, mas de cuidar dos efeitos sociais que derivam das escolhas dos indivíduos. É, no entanto, consensual a necessidade de intervenção do Direito da Família no domínio das crises conjugais, para garantir a defesa do cônjuge mais fraco e regular as relações com os filhos menores, protegendo-os de eventuais situações de risco. ${ }^{2}$

Mas os direitos fundamentais dos pais (o direito à educação e manutenção dos filhos), só podem ser restringidos em situações especialmente previstas na lei, obedecendo às exigências da proporcionalidade e da adequação, em prol da defesa dos direitos da criança. O poder paternal é definido na lei como a obrigação parental de velar pela segurança, saúde e educação dos filhos, prover ao seu sustento, representá-los e administrar os seus bens. O exercício do poder paternal, após o divórcio, é regulado por acordo dos pais e será sujeito a homologação do tribunal, que deve interferir se estes não chegam a acordo ou esse acordo não satisfaz, do ponto de vista do tribunal, os interesses do menor. Deve, nomeadamente, ser estabelecido um regime de visitas ao progenitor a quem o menor não foi confiado atendendo ao interesse deste manter uma relação de grande proximidade com os dois progenitores. Mas o direito de visita é um direito-dever/direito-função que não deve ser exercido no exclusivo interesse do seu titular podendo ser limitado, excluído, ou suspendido provisoriamente, em contexto de um conflito extremo entre o interesse da criança (devendo aqui contemplar-se também a sua vontade) e o direito do progenitor. Extrai-se da jurisprudência que a audição prévia da criança, neste contexto, é a forma mais lídima de auscultar o seu superior interesse. A LPCJ aponta 12 anos, como idade a partir da qual a opinião do jovem é relevante. Em idades inferiores há que avaliar se a criança tem capacidade para compreender a sua situação.

\section{O superior interesse do menor: perspetiva jurídica}

Houve uma mutação acelerada da regulação jurídica da família nas sociedades ocidentais, que apresenta como principais eixos de mudança a consagração do princípio da igualdade, ou seja a democratização da vida familiar. ${ }^{2}$ Para além do privilégio consagrado ao vínculo afetivo notou-se também uma maior responsabilização da esfera pública pela socialização e promoção dos direitos familiares. Neste contexto a expressão 'poder paternal' foi substituída por 'responsabilidade parental' o que, nas palavras do Juiz Conselheiro Armando Leandro, 'acentua o altruísmo deste 
conjunto de faculdades que devem ser exercidas de forma vinculada, de harmonia com a função do direito, consubstanciada no objectivo primacial de protecção e promoção dos interesses do filho, com vista ao seu desenvolvimento integral. De facto, o menor, pela especialidade da sua situação face ao adulto, tem direito a uma protecção especial que lhe preserve o seu futuro e o desenvolvimento harmonioso da sua personalidade, congregando-se essa ideia na expressão 'superior interesse' da criança'.

A lei, porém, não define o que entende por superior interesse da criança, tratando-se de um conceito aberto, a preencher face ao caso em concreto. Qualquer decisão tomada com base neste critério reside na valoração que o julgador faça do facto provado, o que se revestirá sempre de subjetividade. Nesta valoração deve atender-se, designadamente, à disponibilidade afetiva demonstrada pelos progenitores (ou terceira pessoa), ao desejo do menor e à (in) capacidade dos progenitores promoverem o seu harmonioso desenvolvimento. Apesar da subjetividade que o reveste, o critério do superior interesse da criança encontra-se em harmonia com as orientações legais que consideram a vontade da criança como um factor decisivo na resolução de questões que lhe dizem respeito.

\section{A PERÍCIA MÉDICO-LEGAL E/OU PSICOLÓGICA}

Melton et al $^{14}$ concluíram que apenas $37,5 \%$ dos juízes ( $n=53$ ) considera a intervenção do perito médico no processo de regulação das responsabilidades parentais como essencial ou muito útil, recorrendo a maioria (75\%) a este tipo de perícia em apenas $25 \%$ dos casos.

Segundo Bow e Quinnel, ${ }^{15}$ o tempo médio $(9,7$ semanas) necessário à obtenção dos resultados da perícia psiquiátrica/psicológica é uma das principais limitações apontadas pelos juízes/advogados, a qual desmotiva a 'referenciação' do caso. O tribunal tem prazos legais a cumprir e as disputas de custódia, que provocam um grande desgaste emocional aos seus intervenientes, devem ser resolvidas com celeridade. Consideraram ainda os juízes/advogados que as conclusões periciais, para além de pouco objetivas, revelavam falta de conhecimento de critérios legais, tais como o do superior interesse da criança e apontaram a necessidade de relatórios mais completos, contemplando mais fontes de informação e conclusões/ recomendações detalhadas e específicas.

As características mais apreciadas no perito médico são a sua isenção, rigor e ausência de viés (frequente em relatórios redigidos por profissionais que seguem o caso do ponto de vista clínico, dada a relação médico-doente estabelecida), bem como as suas competências de análise das provas, respeitando os limites estabelecidos pelos conhecimentos científicos atuais. ${ }^{15}$ De facto, para que as decisões judiciais sejam justas, no contexto da regulação das responsabilidades parentais, não devem basear-se em experiências pessoais, crenças da sociedade ou intuições de como 'devia ser'. ${ }^{16}$

A realização de perícia médico-legal e/ou psicológica, neste contexto, requer não só conhecimentos sobre a le- gislação vigente, mas também do desenvolvimento e da psicopatologia do menor, da psicopatologia e adaptação do adulto e dos sistemas familiares. Poderão coexistir alegações de abuso do menor (físico, nomeadamente de cariz sexual; emocional; exposição a violência doméstica) ou questões relacionadas com doença mental, comportamentos aditivos e/ou orientação sexual do(s) progenitor(es). ${ }^{15} \dot{E}$ também essencial que o perito médico tenha acesso a toda a informação relevante, sendo que enquadramentos legais distintos implicam diferentes interpretações dos achados médico-legais, influenciando as conclusões da perícia. Não raras vezes, as especificidades do caso limitam a aplicação das evidências científicas existentes. Acresce que a contínua evolução da ciência e as sucessivas adaptações, socialmente determinadas, do conceito de infância impõem ao perito constante atualização e flexibilidade interpretativa.

Mas, apesar das limitações apontadas, os relatórios periciais são o meio mais adequado de providenciar informações relevantes. A existência de normas orientadoras para a sua realização permite avaliações mais uniformes e interpretações mais homogéneas, pela entidade judicial, evitando-se que metodologias periciais divergentes possam inspirar tomadas de decisão díspares em situações semelhantes. Estas normas possibilitam ainda estabelecer parâmetros de qualidade das práticas periciais.

O relatório pericial serve, idealmente, o propósito de esclarecer questões jurídicas suscitadas pelo caso. Mas, na impossibilidade de esclarecer tais dúvidas, pode desempenhar um papel igualmente importante, analisando/ justificando adequadamente a dificuldade em estabelecer os níveis de certeza desejados na apreciação de um determinado facto. Uma das importantes diferenças entre o conhecimento científico e as outras formas de conhecimento é que este se acompanha sempre de uma análise da fiabilidade das suas observações. Pela sua natureza, opiniões científicas nunca são certezas absolutas e as suas limitações devem ser esclarecidas.

É ainda de referir a importância do consentimento informado aceitando-se que, de acordo com a idade (a partir dos 14 anos) e a capacidade de entendimento, o menor possa consentir ou dissentir a perícia. É aqui de extrema importância explicar detalhadamente os procedimentos e objetivos da perícia e esclarecer dúvidas, apaziguando os medos/incertezas do menor. Os pais devem ser informados do papel do perito e das limitações da confidencialidade, nestes casos.

\section{O superior interesse do menor: perspetiva médica e psicológica}

A avaliação de crianças $^{18}$ a vivenciar situações de divórcio parental permitiu identificar diversos factores que influenciam positivamente o seu ajustamento emocional, destacando-se a manutenção de relação afetiva de qualidade com ambos os progenitores. ${ }^{16}$ Encontram-se, no entanto, descritos na literatura inúmeros casos de Síndrome de alienação parental (SAP), termo introduzido pelo Psicó- 
logo Richard Gardner, representando não uma síndrome em sentido clínico, mas antes uma disfunção do vínculo afectivo com um dos progenitores, decorrente de uma campanha negativa sistemática, continuada e intencional, empreendida pelo outro progenitor com o intuito de conseguir uma relação preferencial ou exclusiva com o filho. Neste contexto podem surgir alegações de abuso sexual. Esta teoria é, no entanto, alvo de críticas não negligenciáveis, ${ }^{17}$ não tendo tal conceito sido contemplado na $5^{\text {a }}$ edição do Diagnostic and Statistical Manual of Mental Disorders, publicada pela American Psychological Association. Ainda assim, outras entidades nela abrangidas ('problemas de relacionamento pai-filho'/'criança afetada pela relação parental conflituosa'), podem ser usadas na tentativa de ilustrar esta disfunção. A hostilidade do menor para com o progenitor rejeitado é difícil de interpretar já que pode corresponder apenas à natural evolução de uma relação cronicamente pobre e/ou conflituosa. Entende-se assim que o principal objetivo da perícia não seja estabelecer diagnósticos clínicos, mas analisar a interação pais/filho e avaliar o impacto do tipo de relações familiares existentes no funcionamento/ desenvolvimento psicológico do menor. Relatórios que enfatizam excessivamente termos psicopatológicos nas suas considerações podem ser estigmatizantes e/ou desviar a atenção dos factos que realmente importam. Assim, os resultados periciais só devem ser apresentados através de diagnósticos nosológicos quando tal enquadramento for importante, nomeadamente para avaliar a capacidade do progenitor cumprir as suas obrigações parentais. ${ }^{18}$

Durante o período de adaptação pós regulação judicial das responsabilidades parentais é de atender à possibilidade de ressurgimento de perturbações psicológicas/comportamentais do menor, podendo ser importante (re)avaliar (tendo em conta o carácter probabilístico das conclusões periciais) a criança, mesmo na ausência de sinais físicos de abuso e alterar, se adequado, o regime de visitas ou mesmo de custódia (em detrimento do outro progenitor ou de terceiros). Não obstante, qualquer relatório pericial será livremente apreciado pelo juiz, que pode afastar-se das conclusões se as reputar incorretas.

\section{ABUSO SEXUAL}

A coexistência de alegações de abuso sexual em casos de regulação das responsabilidades parentais torna ainda mais desafiante a perícia. É comum, em contexto familiar, a partilha da cama entre adulto e criança, bem como o toque nos seus genitais (ao ajudá-la a tomar banho/vestir-se). Não raras vezes as suspeitas de abuso surgem da exagerada atenção/importância dada a estas atividades quotidianas, especialmente se a criança e o progenitor não partilham o mesmo género. De facto, quando um dos progenitores, desconfiando do outro, demonstra, mesmo que inconscientemente, elevados níveis de preocupação, questionando insistentemente a criança sobre tudo o que se passa na sua ausência, acaba por lhe transmitir a sua ansiedade. A consequente apreensão da criança relativamente a um dos progenitores pode levar à conclusão (pre- cipitada), por parte de terceiros, de que algo inapropriado aconteceu. ${ }^{18}$ Impera assim que os profissionais de saúde que lidam com casos de disputa de custódia adotem um verdadeiro 'espírito forense' de busca de factos.

Do ponto de vista pericial é importante ouvir a versão de ambos os progenitores, podendo mesmo justificar-se entrevistar terceiros (com relação de proximidade com a família), esta atitude é essencial para compreender a dinâmica familiar e explorar a veracidade da alegação. Para tomar decisões sobre a custódia poderá justificar-se a aplicação de testes psicológicos ao menor e/ou aos progenitores, bem como a observação da criança em interação com cada um dos progenitores. Deve ainda ser disponibilizada ao perito toda a informação relevante, nomeadamente clínica. ${ }^{19}$

Tendo em conta a dificuldade em estabelecer o diagnóstico médico-legal de abuso sexual por ausência ou inespecificidade das evidências físicas e a existência de sintomas comuns aos apresentados por crianças que vivenciam uma separação parental conflituosa, entende-se como inaceitável afastar um dos progenitores sem avaliar o seu relacionamento com a criança e com o outro progenitor. É fundamental tentar perceber qual o comportamento habitual desse progenitor antes da separação, nomeadamente se demonstrava interesse pelo filho, bem como contextualizar a acusação de acordo com a dinâmica familiar, tendo em consideração fatores como a sequência temporal (a alegação ocorreu antes ou depois do divórcio), quem apresentou a queixa, a existência de queixas/alegações anteriores e os motivos potencialmente envolvidos.

\section{O Testemunho do Menor}

Outro aspeto a considerar é que a dificuldade em provar o alegado abuso torna muitas vezes essencial o relato da vítima, neste caso a criança. Historicamente sempre houve interesse na capacidade de 'testemunho' do menor, sobretudo numa perspetiva pré-sentencial, funcionando deste modo como elemento a considerar na decisão judicial. ${ }^{20}$ Sabe-se atualmente que crianças com sete anos de idade são capazes de contar a história de um evento de forma muito precisa, desde que não questionadas de forma sugestiva. Por outro lado, a criança no centro de um conflito de custódia está normalmente exposta a opiniões de adultos significativos, nomeadamente da figura parental de referência, o que pode imputar um viés não negligenciável na sua percepção e interpretação dos eventos. As crianças muitas vezes respondem a uma questão sugestiva (enviesada) aquilo que o seu interlocutor parece desejar. ${ }^{18}$

Binet $^{21}$ distinguiu entre os erros de testemunho causados por alterações de memória efetiva daqueles causados por conformidade social, argumentando que estes últimos surgem na tentativa de agradar ao entrevistador, podendo a memória do evento encontrar-se íntegra. Com isto, deu início ao debate que decorre atualmente sobre se a memória sugestionada afeta/substitui a memória primitiva ou se podem 'coexistir'. O conceito de sugestionabilidade interrogativa refere-se ao grau em que a codificação, armazenamento e a evocação de memórias, podem ser in- 
fluenciadas ou deturpadas por factores psicossociais. De acordo com Stern, ${ }^{22}$ um dos fundadores da psicologia do desenvolvimento, em entrevistas repetidas sobre o mesmo evento o indivíduo relembra mais facilmente as primeiras respostas verbais do que o evento em si, podendo o próprio entrevistador, de acordo com a formulação das questões, ser responsável pela ausência de fiabilidade dos testemunhos. Acresce que as crianças entendem as perguntas como imperativas, preferindo dar uma resposta, ainda que 'falsa', do que revelar que não se lembram/não sabem. Lipmann ${ }^{23}$ considera que as crianças, quando questionadas por adultos significativos, sobre temas sem grande relevância, tendem a corrigir a sua memória, tornando o relato consistente com a questão. A criança tende a 'usar' qualquer informação, real ou imaginária, para preencher as 'falhas' na memória, passando eventualmente a interpretar o conteúdo que imaginou como sendo real. A obra de Lipmann influenciou as diretivas atuais que desaconselham múltiplas entrevistas sobre o mesmo evento e privilegiam o recurso à evocação livre em detrimento do uso de questões fechadas, evitando-se assim sugestionar o relato. ${ }^{24,25}$ Assume-se assim que se a entrevista for bem dirigida, as crianças conseguem contar uma história corretamente, englobando os detalhes mais importantes. ${ }^{26}$

\section{CONCLUSÕES E PERSPETIVAS FUTURAS}

A Convenção sobre os Direitos da Criança, não estabelecendo uma idade específica, afirma que o menor deve ser ouvido, desde que capaz de formular uma opinião. Assim, apesar da idade e maturidade do menor influenciarem o peso atribuído à sua perspetiva este poderá/deverá expressá-la. Ouvir e considerar a opinião do menor não é mais do que respeitar a sua autonomia e dignidade, enquadrando uma exigência ética. É importante atender às suas experiências e pontos de vista de forma a assegurar a sua inclusão na tomada de decisão. Este procedimento cumpre ainda o objetivo genérico de incutir valores democráticos e de cidadania, sendo que a participação do menor no processo de decisão o obriga a ponderar as possíveis repercussões da decisão judicial na sua vida, eventualmente, contribuindo para melhores decisões e acordos judiciais mais viáveis. Há no entanto que ressalvar que falamos de um direito, não de uma obrigação, podendo o menor optar por não expressar qualquer opinião, se assim o entender.

A avaliação pericial psiquiátrica e/ou psicológica surge aqui como importante alternativa à audição do menor em tribunal, assegurando-se que a entrevista é conduzida/ formulada adequadamente e o testemunho interpretado de acordo com a sua idade e circunstâncias. Acresce que, procurar responder às questões 'quem', 'como', 'quando' e 'porquê', face a um caso em concreto, obtém-se não só pela análise dos factos relatados, mas também pela recolha de toda a informação disponível (proveniente de diferentes fontes), podendo ser necessários exames complementares (nomeadamente neuropsicológicos aferidos e validados em contexto nacional, toxicológicos e/ou de neuroimagem). A partilha de dúvidas com outros profissionais especializados pode ser igualmente útil.

É, no entanto, essencial ter presente que à opinião de um especialista corresponde, de acordo com a classificação de Oxford, o nível menor (5) de evidência científica numa escala de cinco níveis. Quanto menor o nível de evidência menor a força da prova científica, sendo que ao nível máximo (1) de evidência correspondem os estudos randomizados, duplamente cegos. Importa assim que o julgador entenda a importância da perícia, já que esta é adapatada ao caso em concreto, mas que, considere e respeite as suas limitações.

As decisões judiciais têm por base o superior interesse da criança, conceito que por um lado permite adaptar a decisão ao caso em concreto mas por outro potencia a heterogeneidade dos factores considerados nas decisões, deixando ampla margem à inclusão de juízos de valor em tais vereditos. Parece pertinente que, através da análise dos elementos comuns dos casos de regulação das responsabilidades parentais a nível nacional/europeu, sejam estabelecidos critérios objetivos e funcionais que possibilitem estabelecer algumas diretivas orientadoras da diligência judicial. É igualmente de estimular que prévia ou paralelamente às medidas judiciais, seja promovida a atenuação do conflito familiar e da litigiosidade, nomeadamente através de acordos uma vez que os compromissos livremente aceites são mais facilmente cumpridos. Importa desjudicializar a resolução destes conflitos, fomentando uma justiça negociada e de proximidade, praticada por entidades administrativas, através de mediação e/ou conciliação. Ouvir e respeitar a opinião do menor, sempre que as circunstâncias o permitam, pode evitar o litígio ou a sua persistência que, em boa verdade, nada contribui para o seu bem-estar biopsicossocial.

\section{CONFLITO DE INTERESSES}

Os autores declaram que não houve conflito de interesses na realização deste trabalho.

\section{FONTES DE FINANCIAMENTO}

Os autores declaram a inexistência de fontes de financiamento externas.

\section{REFERÊNCIAS}

1. Kant I. Fundamentação da metafísica dos costumes. São Paulo: Companhia Editora Nacional; 1964.

2. Pedroso P, Branco P. Mudam-se os tempos, muda-se a família. As mutações do acesso ao direito e à justiça de família e das crianças em Portugal. Rev Crit Cienc Soc. 2008;82:53-83.

3. Oliveira G. Temas de Direito da Família. $2^{\mathrm{a}}$ ed. Coimbra: Coimbra Editora; 2001.
4. Scott E, Reppucci D, Aber M. Children's preference in adjudicated custody decisions. Georgia Law Ver. 1987;22:1035.

5. Meneses R. Principalismo e pedagogia: entre a ética e a educação. Eukasia: Rev Filos. 2007;189-216.

6. Damásio A. O Erro de Descartes: emoção, razão e cérebro humano. Lisboa: Círculo de Leitores; 1995.

7. Piaget J. The origins of intelligence in children. New York: The Norton 
Library; 1962.

8. Espinosa B. Tratado Político. São Paulo: WMF, Martins Fontes; 2009.

9. Thomas M. Comparing theories of child development. Camberra: Thomson/Wadsworth; 2005.

10. Pardess $E$. Evaluating the best interests of the child: a model of multidisciplinary teamwork. Med Law. 1993;12:205-11.

11. Piaget J. The moral judgement of the child. New York: The Free Press Paperbacks; 1997.

12. Scott E, Steinberg L. Rethinking juvenile justice. Harvard: Harvard University Press; 2008.

13. Neto L. Os limites da ciência do direito. Interacções. 2006;3:4-18.

14. Melton $\mathrm{G}$, Weithorn $\mathrm{L}$, Slobogin $\mathrm{C}$. The community mental health centers and the court: An evaluattion of community-based forensic services. Lincoln: University of Nebraska Press; 1985.

15. Bow J, Quinnell F. Critique of child custody evaluation by the legal profession. Fam Court Rev. 2004;42:115-27.

16. Mlyniec W. A judge's ethical dilemma: assessing a child's capacity to choose. Fordham Law Rev. 1996;64:1873-915.

17. Kelly J. The determination of child custody. Future Child. 1994;4:12142.

18. Greenberg L, Martindale A, Gould J, Gould-Saltman D. Ethical issues in child custody and dependency cases: enduring principles and emerging challenges. J Child Custody. 2004;1:7-30.

19. Bow J, Quinnell F, Zaroff M, Assemany M. Assessment of sexual abuse allegations in child custody cases. Prof Psychol Res Pr. 2002;33:566-75.

20. Gonçalves R. Psicologia forense em Portugal; uma história de responsabilidades e desafios. Anal Psicol. 2010;1:105.

21. Binet A. La Suggestibilite (e-book). Curtis Weyant, Renald Levesque and PG Distributed Proofreaders; 2004 [Consultado 2012 Set 20]. Disponível em: http://www.gutenberg.org.

22. Stern W. Abstracts of lectures of the psychology of testimony and on the study of individuality. Am J Psychol. 1910;21:270-82.

23. Lipmann O. Pedagogical psychology of report. J Educ Psychol. 1911;2:253-61

24. Ceci S, Bruck M. Suggestibility of the child witness: a historical review and synthesis. Psychol Bull. 1993;113:403-39.

25. Bow J, Quinnell F. Psychologists current practices and procedures in child custody evaluations: five years after American Psychological Association guidelines. Prof Psychol Res Pr. 2001;32:261-8.

26. Rudy L, Goodman G. Effect of participation on children's reports: implication's for children's testimony. Dev Psychol. 1991;27:527-38. 


\section{O Respeito pela Autonomia da Criança na Regulação das Responsabilidades Parentais \\ Acta Med Port 2013:26:637-643}

Publicado pela Acta Médica Portuguesa, a Revista Científica da Ordem dos Médicos

Av. Almirante Gago Coutinho, 151

1749-084 Lisboa, Portugal.

Tel: +351218428215

E-mail: submissao@actamedicaportuguesa.com

www.actamedicaportuguesa.com

ISSN:0870-399X | e-ISSN: 1646-0758

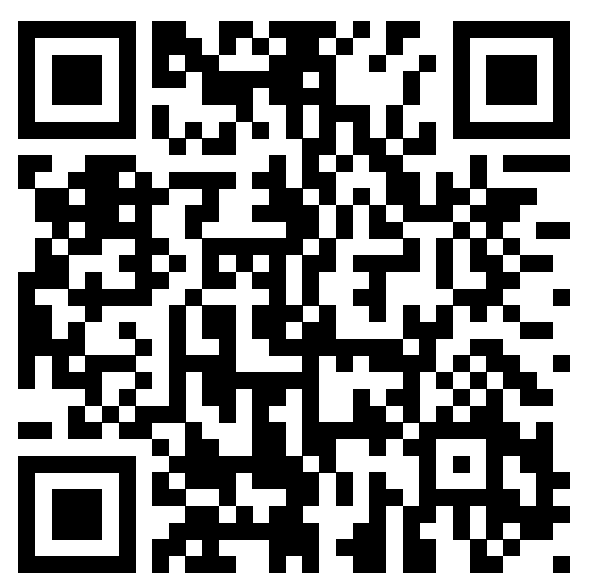

